\title{
Advancing Multilevel Alliance Research: Rejoinder to Commentary on Cui and Kumar
} (2012) and Future Directions

\author{
Anna S. Cui \\ Department of Managerial Studies \\ College of Business Administration \\ University of Illinois at Chicago \\ 601 S Morgan Street, Chicago IL 60607 \\ Tel: 312-996-7326 \\ Email: ascui@uic.edu
}

\author{
Shyam Kumar \\ Lally School of Management and Technology \\ Rensselaer Polytechnic Institute \\ 1108 th street \\ Troy, NY 12180 \\ Tel: 518-276-2961 \\ Email: kumarm2@rpi.edu
}

Forthcoming at Journal of Business Research 


\begin{abstract}
We respond to the comments raised by Nielsen (2012) in his commentary essay on Cui and Kumar (2012). While concurring with Nielsen's (2012) observations regarding appropriate level of measurement and the importance of relational aspects of JVs, our response elaborates on how these issues play a role in a research program adopting a multilevel approach to alliances/ JVs. We also identify some further avenues and research questions.
\end{abstract}




\section{Introduction}

In our study "The termination of related and unrelated joint ventures: a contingency approach" (Cui and Kumar 2012), we compared the impact of various factors on joint venture (JV) termination for related and unrelated JVs. Nielsen's (2012) commentary essay provides valuable comments on our study and raises some interesting issues. These include the operationalization of JV relatedness, the treatment of the relational aspects of JV evolution, and the development of a coherent multilevel theoretical framework. Here we intend to provide clarity to these questions as well as further discuss multilevel research in strategic alliances/JVs.

\section{Operationalization of JV relatedness}

JV relatedness represents the similarity in resources and capabilities between the JV and the parent firm. In our study we measured relatedness by comparing a JV's two-digit SIC code with its parent firm's primary SIC code. SIC codes provide a good proxy for firm resources and capabilities because in contrast with businesses in different industries, businesses in the same industry tend to have similar assets and operations, as well as similar intangible resources such as market knowledge, manufacturing processes and management expertise (Wang and Zajac 2007; Kumar, 2010).

While various limitations are pointed out with this approach, Nielsen's (2012) main critique is that in our approach the level of measurement is not consistent with our theoretical construct. Thus while our objective is to capture relatedness at the JV level, we use data at the industry level for this purpose.

This mismatch is a reflection of the constraints that a researcher typically faces when conducting research in the alliance and JV domain. The problem we encountered in our study 
was one of measuring relatedness, rather than a lack of recognition of the different levels of analysis involved. Inconsistency among levels of theory, measurement and analys is involves situations such as transferring a construct from one level to another level as a consequence of which the meaning of the construct itself changes (Nielsen 2010). In our case by proxying JV relatedness using industry similarity, the meaning of the construct does not fundamentally change because of the transitive property of relatedness (i.e. if the JV and the firm's industries are related, then it is likely that the JV and the parent firm's core business are also related). This transitivity may not extend to other situations. For example a group level attribute such a performance in a certain task is often not merely the sum of the lower level individual level attributes along this dimension. In our view a careful distinction needs to be drawn between the two situations.

As another example, consider research that examines the role of alliances in innovation. This research measures knowledge flows in alliances by looking at changes in cross citations of parent firms before and after the alliance. The measurement is at the firm level rather than the alliance level, since it is difficult to isolate changes in cross citations specifically due to the alliance. This approximation is reasonable given the data constraints. But it does not fundamentally alter the meaning of the construct, in this case knowledge flows between firms due to the alliance. Hence it should not prevent us from investigating a fundamentally important theoretical question, namely, how do multiple levels of analysis interact to influence the relationship between innovation and collaboration?

As scholars pursue multilevel research, they are likely to resort to using some of the established measures in existing literature when conducting various empirical tests. We concur with Nielsen (2012) that when using such measures scholars need to be sensitive to whether the 
measures were constructed at a higher/lower level of aggregation. Where there is a potential mismatch in levels, scholars should carefully discuss how this does not violate construct validity and change the meaning of construct. When the integrity of the construct is maintained, the practical constraints posed by measurement need to be weighed against their benefits in terms of testing novel theoretical propositions related to multilevel research.

\section{Relational aspects of JV evolution and outcomes}

Nielsen (2012) notes that in our study we do not examine the objective of the JV at the time of formation, but only focus on its relatedness. Further, he rightly observes that our study focuses mainly on structural characteristics chosen ex-ante prior to the commencement of the partnership, such as the scope of the alliance/JV and ownership structure, and does not consider ex-post processes which may also impact termination. These include the degree of coordination, and the presence of adaptive governance mechanisms.

Our study draws on the argument that JV relatedness indirectly reflects different emphases on exploration and exploitation for the parent firm (Koza and Lewin, 2000). Consequently, given these intrinsic differences, unrelated JVs are likely to exhibit certain tendencies which may be prevalent over the duration of the JV, notwithstanding ex-post adaptive processes. For example, unrelated JVs are likely to be less vulnerable to environmental changes given that they are likely to be more exploratory in nature and have more option value from the parent firm's perspective, irrespective of the ex-post processes they adopt. Similarly, other ex-ante characteristics and structural features have also been shown to consistently predict rates of termination in prior research independent of ex-post adaptive processes, including ownership structure (e.g. Killing, 1983) and the degree of competition between partners (Park and Russo, 1996).

While these ex-ante variables have been extensively used in prior research, the question that warrants attention is do they have any role to play in multilevel research given that they do not reflect ex-post adaptive processes? We submit that the answer is yes. To elaborate further, consider for example JV 
scope. One cross level interaction that can be explored is whether at any given point in time the effect of JV scope on termination will vary based on parent firm scope (i.e. a parent firm whose scope has gradually increased over time may have a greater propensity to terminate a JV with a broad scope, compared to a firm whose scope has remained stable). This cross level effect captures the coevolutionary dynamics between a JV and a parent firm (Cui, Calantone and Griffith, 2011). The effects are likely to be observed notwithstanding the trust and relational mechanisms developed within the JV, since its locus is the parent-JV link rather than the processes within the collaboration. Similarly, another ex-ante choice that may also exhibit cross level effects and may be important from a coevolutionary perspective is ownership structure. For example a JV with a certain ownership structure (e.g. minority equity ownership) may face a propensity for termination that is conditional on the leverage of the firm (a highly levered firm may prefer pursuing minority ownership structures for maximum flexibility; consequently if leverage increases over time, majority JVs may be more prone to termination).

Relational aspects no doubt have a critical role to play in predicting JV evolution and termination. Yet the importance of structural features and governance mechanism chosen ex-ante cannot be under emphasized, and in our view these considerations are likely to be equally important from a multilevel research perspective given that they capture co evolutionary effects.

\section{Future directions}

While so far calls for adopting a multilevel approach have been at high levels of generality, Nielsen (2010b) provides an excellent illustration of how to advance such an agenda with a very specific example that can be empirically tested. Our objective here is to also provide such specificity when making recommendations for the future.

As we noted above, one direction to pursue is to examine coevolutionary effects between the JV and the parent firm. Another potential starting point we suggest is to ask the question, what is the relative explanatory power of the different levels of analysis with regard to various alliance/JV related phenomena? In doing so we borrow a page from studies in the strategy literature that have examined how 
variance in performance is attributable to factors at the business unit, industry, and firm levels of analyses (e.g. McGahan and Porter, 1996). We think a similar approach holds considerable potential for alliances and JVs. Thus it would be useful to empirically study what proportion of the variance in alliance performance is attributable to the alliance, dyad, network, and the parent firm levels of analysis. Similarly it would also be useful to examine variance in knowledge flows and innovative output of alliances, and the relative effect of each of these factors in explaining this variance.

In pursuing this line of inquiry, researchers could also identify new variables and theoretical relationships which have so far not been tested. A multilevel approach offers a fundamentally different epistemological framework within which novel knowledge claims can be developed and tested. For example, one question that is worthwhile exploring is if initial conditions such as early success or failure with alliances promote a faster rate of learning, and hence have a lasting impact on the firm's subsequent alliance performance. Such effects would demonstrate the importance of imprinting (Stinchcombe, 1965) in alliance evolution. In addressing this question, early success/failure can be incorporated as a firm fixed effect along with other firm level variables within which individual alliance performance is nested.

As another example, consider the presence of an alliance function (Kale, Dyer and Singh, 2002), which similar to imprinting, is a firm fixed effect that is likely to having a systematic impact on multiple alliances. Prior research suggests the presence of an alliance function enhances alliance performance. But there is considerable potential for expanding this line of inquiry. For example, using multilevel theorizing one could also test the claim that firms with an alliance function systematically enter into broader scope alliances, since the presence of an alliance function helps them control unintended knowledge flows much more carefully. In this case the alliance function would be a higher order firm fixed effect within which multiple alliances are nested. Similarly, another testable hypothesis that involves cross level interactions is that firms with an alliance function are also able to collaborate more successfully with competitors in their own industry. This is in contrast with prior research which suggests partnerships with competitors are generally more unstable. In this case relatedness at the JV level would interact with the presence/ 
absence of an alliance function at the firm level in a model with alliance stability as the dependent variable.

Besides these firm fixed effects, a researcher could ask the question, is it possible that CEOs have specific alliance capabilities and know how which they transfer across firms? Some studies in the finance literature show that that there is the presence of a 'CEO style' which affects multiple strategic decisions such as R\&D expenditures, advertising expenditures, diversifying acquisitions etc. (Bertrand and Schoar, 2003). It would be worthwhile exploring if such style effects also exist in the case of alliances. In this investigation, the CEO would constitute the higher order of analysis within which alliances/ JVs formed by the CEO in individual firms would be nested. If there is significant variance explained by the CEO level, the researcher can then infer the presence of a CEO alliancing style.

As another direction, apart from firm and CEO fixed effects, a researcher could also investigate the impact of network characteristics. Here the approach would involve examining multiple networks, and looking at how within each network the characteristics of alliances are affected by properties of that particular network (i.e. the network is the higher level within which multiple alliances are nested). Recent approaches have attempted to develop a typology of networks (Rosenkopf and Schilling, 2007) such as disconnected, hybrid and spiderwebs. This typology is based on the degree of subs groups with the networks, and the degree of connectedness among various players. The typology once again presents an opportunity in the sense that researchers can test whether some types of networks systematically influence alliance characteristics (e.g. alliances formed within disconnected networks systematically have lower scope because of the lack of social relations that act as a sanctioning mechanism against opportunistic behavior).

\section{Conclusion}

In this response to Nielsen (2012) we provide three observations. First, we note that as researchers construct empirical measures to test multilevel theories, if there is a mismatch between the level of measurement and the level of the theoretical construct, then they should ensure that the meaning of the 
construct is itself not changed by the aggregation/disaggregation. Second, while process level issues play a critical role in understanding alliances/JVs, initial choice variables such as governance structure and scope also have a valuable role to play in a multilevel research program, for example to test coevolutionary effects. Our third observation is that opportunities for conducting multilevel research in alliances/JVs abound. Severaldirections are possible, including unpacking the variance explained by various levels of analysis, and theoretically testing the impact of novel fixed effects. Ultimately we are in full agreement with Nielsen (2012) and we hope our response spurs further research adopting a multilevel approach. 


\section{References}

Bertrand, M., \& Schoar, A. (2003). Managing with style: the effect of managers on firm policies. Quar J Econ, 118, 1169-1208.

Bryce, D.J. \& Winter, S.G. 2009. A general inter industry relatedness index. Manag Sci, 55, 9, 15701585.

Cui, A. S., Calantone, R. J., \& Griffith, D. (2011). Strategic change and termination of interfirm partnerships. Strat Manag J, 32, 402-423.

Cui, A. S., \& Kumar, S. (2012). The termination of related and unrelated joint ventures: a contingent approach. J Bus Res.

Kale, P., Dyer, J. H., \& Singh, H. (2002). Alliance capability, stock market response, and long-term alliance success: The role of the alliance function. Strat Manag J, 23, 747-767.

Killing, J. P. (1983). Strategies forjoint venture success. New York: Praeger.

Koza M. P., \& Lewin, A.Y. (2000). Managing partnerships and strategic alliances: raising the odds of success. Euro Manag J, 18, 146-151.

Kumar, M.V.S. (2009). The relationship between product and international diversification: The effect of short run constraints and endogeneity. Strat Manag J, 3, 99-116.

Kumar, M.V.S. (2010). Differential gains between partners in joint ventures: Role of resource appropriation and private benefits. Org Sci, 21, 232-248.

Nielsen B.B. (2010). Strategic fit, contractual, and procedural governance in alliances. J Bus Res, 63, 682689.

Nielsen B.B. (2010b) Multilevel issues in strategic alliance research. In T. K. Das (Eds.), Researching strategic alliances: emerging issues (pp1-26). Charlotte, NC: Information Age Publishing.

Nielsen, BB. (2012). What determines joint venture termination? A commentry essay. J Bus Res.

Park, S.H., \& Russo, M. (1996). When competition eclipses cooperation: An event history analysis of joint venture failure. Manag Sci, 42, 875-890.

Rosenkopf, L. \& Schilling, M. (2007). Comparing alliance network structure across industries: observations and explanations. Strat Entre J, 1, 191-209.

Stinchcombe, A. L. (1965). Social structure and organizations. In J. G. March (Eds.), Handbook of organizations (pp. 142-193). New York: Rand McNally.

Wang, L., \& Zajac, E. J. (2007). Alliance or acquisition? a dyadic perspective on interfirm resource combinations. Strat Manag J, 28, 1291-1317. 